\title{
The Nature and Measurement of Learning from Attending a Public Lecture on Human Genetics Léonie Rennie and Gina Williams
}

It is easy to think that much of the important scientific research today concerns genetics. In the last few weeks of 1999, The West Australian daily newspaper carried articles linking genetics with modified foods, environmental concerns, medical care, genetic diseases and the possibility of their prevention. This burgeoning information base calls for increasing public understanding of these issues ${ }^{1}$. Turney sums it up:

\begin{abstract}
DNA dreams and gene nightmares have been an important part of our collective image of science these last four decades. Today the volume of academic commentary on the human genome project, let alone journalistic or fictional depictions of genetics, is becoming almost overwhelming. This poses as important problem for public understanding of science. To what extent might it be possible to make sense of this whole area for debate, and which frameworks will be most helpful in trying to do so ${ }^{2}$
\end{abstract}

This 'whole area for debate' has come to be called the 'new genetics', that is, 'the development and deployment of recombinant DNA techniques in relation to human disease $^{\prime 3}$. Macintyre points out that the new genetics will have implications in three major areas: the screening for carriers of inherited disorders, the identification of those with a particular disorder, and gene therapy for those affected ${ }^{4}$. Having knowledge about genetics and DNA is thus important but insufficient. People also need some understanding of, and ability to deal with, the moral and ethical issues that arise when the techniques and processes of the new genetics are used deliberately to intervene in human lives.

One avenue to information and understanding about human genetics, a series of public lectures, entitled Genetics: The Facts, Fiction, Issues and Ethics, was evaluated in terms of its impact on attendees' perceptions, ideas and opinions about human genetics. The nine, monthly evening lectures were presented by Western Australian scientists involved with Perth universities, hospitals and research institutes. The lectures were held at Scitech Discovery Centre, sponsored by the Hereditary Disease Program, Health Department of Western Australia and supported by the Human Genetics Society of Australasia. In this article the results are reported. The methodological decisions that had to be made about what kind of learning is likely to eventuate from attending a public lecture on human genetics and how it might be measured are also discussed.

Public lectures like this series have several features in common. They usually are short, anyone can attend, and they cover topics thought to be of interest to the community. There is a notion of service to the public by providing access to contemporary information and research in science. The organisers explained that:

Scitech Discovery Centre wanted to educate, inform and enlighten the community about the exciting developments in DNA and genetics, and the Hereditary Disease Program wanted to

\footnotetext{
${ }^{1}$ Thomas R. Mertens \& Jon R. Hendrix, 'The popular press, scientific literacy in human genetics, and bioethical decision-making', School science and Mathematics, vol. 90, no.4, 1990, pp. 317-322; Martin Richards, 'Lay and professional knowledge of genetics and inheritance', Public Understanding of Science, vol. 5, 1996, pp. 217-230.

2 J. Turney, 'Public Visions of genetics', Public Understanding of Science, vol. 7, 1998, pp. 343.

${ }^{3}$ Richards, op. cit., p. 217.

${ }^{4}$ S. Macintyre, 'The public understanding of science or the scientific understanding of the public? A review of the social context of the 'new genetics"', Public Understanding of Science, vol. 4, 1995, pp. 223-232.
} 
promote [public understanding of] genetics, inherited diseases and the outstanding genetics research being carried out in Western Australia, nationally and internationally. ${ }^{5}$

Like most other free-choice learning experiences, lecture series are rarely evaluated in a comprehensive way, so it was difficult to find material to help us to design our own study. Most relevant was Stutchbury's initial evaluation of 'Science in the Pub', a series of public lectures presented by well-known science communicators in a Sydney hotel ${ }^{6}$. Stutchbury collected her data at five of the first six lectures attended by about 350 people. Attendees were asked whether they had enjoyed the lecture and whether they had learned something new. Although $72 \%$ said they had learned something new, any expansion of this tended to be quite general. Demographic data suggested the non-scientific public and the local community had not been attracted, one of the aims. We found little else to advise this study. Consequently, we turned to the literature on the public understanding of science and scientific literacy to guide our approach.

\section{Measuring People's Awareness about Human Genetics}

Much survey research of people's knowledge of scientific vocabulary and processes as measures of public understanding of science or scientific literacy reports an ignorant public. For example, Miller estimated the percentage of adults qualifying as civic scientifically literate in twelve countries to range from $1 \%$ to $12 \%^{7}$. In contrast, data collected in a more interactive way describes a public that is far more knowledgeable and thoughtful than the survey research might suggest. For example, Doble concluded from an intervention study that, given access to information and opportunity to interact with it, the public can assess thoughtfully issues which are scientifically complex and contain a great deal of uncertainty ${ }^{8}$. Kerr, Cunningham-Burley and Amos found the members of their focus groups had knowledge about the new genetics that could be categorised as technical, methodological, institutional and cultural. They concluded that 'lay people have valuable knowledge and understanding of the social world which equips them to discuss the new genetics in a sophisticated and reflexive manner'. ${ }^{9}$

The diversity of the findings from these different research approaches has significant implications both for the effectiveness of communication between scientists and the public and the way the impact of that communication might be assessed. The common assumption that public understanding of science will improve if people are given more information is based on a deficit model of their understanding. But, as Gross points out, the deficit model works only if the aim is to transfer relevant scientific knowledge from the

\footnotetext{
${ }^{5}$ B. Durston, A. Ghisalberti \& D. Moore, (eds.), The Proceedings of the 1998 Lecture Series Genetics: The facts, fiction, issues and ethics, Perth, Western Australia, 1999, p. 3.

${ }^{6}$ R. Stutchbury, 'Science in the pub', in S. Stocklmayer \& T. Hardy (eds.), Proceedings of the International Conference on Learning Science in Informal Contexts, Canberra, 1999, pp. 54-65. The series has become commercially successful and is now broadcast on Radio National. Further evaluations should provide interesting information.

${ }^{7}$ J. D. Miller, 'The measurement of civic scientific literacy', Public Understanding of Science, vol. 7, 1998, pp. 203-223.

${ }^{8}$ J. Doble, 'Public opinion about issues characterised by technological complexity and scientific uncertainty', Public Understanding of Science, vol. 4, 1995, pp. 95-118.

${ }^{9}$ A. Kerr, S. Cunningham-Burley \& A. Amos, 'The new genetics and health: mobilizing lay expertise', Public Understanding of Science, vol. 7, 1998, pp. 152.
} 
experts to the public ${ }^{10}$. Rarely does this happen. People do not absorb scientific knowledge, unchanged, from any source ${ }^{11}$. To begin with, people are likely to be receptive to scientific information only if it is perceived to be useful to them. Then, they restructure its meaning to suit their own needs, translating and reworking knowledge into a form that they can use in their own personal circumstances. Wynne concludes that

when people do see a personal or practical use for scientific understanding and are sufficiently motivated, they often show a remarkable capacity to learn and to find relevant sources of scientific knowledge. ${ }^{12}$

This suggests that a contextual or interactive model of public understanding of science is more useful than a deficit model because it acknowledges the active role of people in building their own knowledge. Public understanding is the joint product of scientific and local knowledge ${ }^{13}$. Effective communication between experts and the lay public must be a two-way process, so it is not surprising that calls for better public understanding of science now also call for the scientists to better understand the public ${ }^{14}$ !

The contextual or interactive model highlights two issues of importance to the present study. First, 'the public' is not a single-minded group of lay people or nonscientists. Silverstone makes this clear:

There are many publics for science: the specialist and the lay, the interested and the disinterested, the powerful and the powerless; young and old; male and female. While these publics will share much, they will also understand or misunderstand, remember or forget, in different ways. ${ }^{15}$

A heterogeneous public means that effective communication during a lecture and the measurement of its impact must take into account the likely variety among the audience. As a group, members of the audience share a common characteristic in that they are sufficiently interested to attend, but their inherent variety will result in a range of outcomes.

The second issue is that there is no one, true science. As Lévy-Leblond notes, 'science does not produce absolute and universal truths; on the contrary, it yields only conditional statements' ${ }^{16}$. In his opinion, no assessment of public understanding of science can ignore the relative character of scientific knowledge. Further, because scientific

\footnotetext{
${ }^{10}$ A. G. Gross, 'The roles of rhetoric in the public understanding of science', Public Understanding of Science, vol. 3, 1994, pp. 3-23.

${ }^{11}$ See, for example, E. W. Jenkins, 'Public Understanding of science and science education for action', Journal of Curriculum Studies, vol. 26, no.6, 1994, pp. 601-611; D. Layton, 'Science Education and Praxis: The Relationship of School Science to Practical Action', Studies in Science Education, vol. 19, 1991, pp. 4379; D. Layton, E. Jenkins, S. Macgill \& A. Davey, Inarticulate Science, Nafferton, East Yorkshire, 1993.
}

12 B. Wynne, 'Knowledges in context', Science, Technology, \& Human Values, vol. 16, no.1, 1991, p. 117.

${ }^{13}$ Gross, op. cit., p. 69.

14 J-M. Lévy-Leblond, 'About misunderstandings about misunderstandings', Public Understanding of Science, vol. 1, 1992, pp. 17-21; S. Macintyre, 'The public understanding of science or the scientific understanding of the public? A review of the social context of the 'new genetics", Public Understanding of Science, vol. 4, 1995, pp. 223-232; J. Turney, 'Public Understanding of science', Lancet, vol. 347, 1996, pp. 1087-1090.

${ }^{15}$ R. Silverstone, 'Communicating science to the public', Science, Technology, \& Human Values, vol. 16, 1991, p. 106.

${ }^{16}$ Lévy-Leblond, op. cit., p. 18. 
knowledge is contextual, the answer to a question cannot be given meaning in the abstract. Thus, scientific expertise is not about knowing a large body of abstract results, it is 'knowing how to know: where to look, what to read, whom to ask-and why to bother' ${ }^{17}$. Lévy-Leblond's ideas are consistent with those of Shamos who asserts that, in terms of scientific literacy, 'what we seek is a society that (a) is aware of how and why the scientific enterprise works and of its role in that activity, and (b) feels more comfortable than it presently does with science and technology ${ }^{18}$. Measurement of effective communication therefore, would concentrate not on people's ability to remember specific bits of knowledge, but on whether their science-related experience has helped them to think differently and more confidently about science.

Based on our review, we decided that the impact of the lecture series on human genetics could best be measured by concentrating on people's perceptions, ideas, and opinions about human genetics. Thus, we focused not on conceptual and definitional knowledge, but on people's awareness about the nature of human genetics, including its research and its effects on society, and how comfortable they felt in dealing with it.

\section{The Potential Impact of the Lecture Series}

Despite the promising potential for learning and the interested audience, we knew that the impact of the lectures would be difficult to capture for several reasons. First, the lectures were transitory events lasting about one hour including questions at the end. This short time span limits the potential impact of a lecture. Also, lectures differ in content and presentation, and as different people attend different numbers and combinations of lectures, they are likely to experience different levels of impact.

Second, people vary. They have different background knowledge, past experiences, current circumstances and expectations of the lecture, leading to different potentials for learning. For example, someone interested in a particular topic and actively seeking information may learn a great deal from a lecture. Another interested person with extensive background knowledge may thoroughly enjoy the lecture, but has less potential for either cognitive or affective learning. A person with limited knowledge might find the lecture too difficult to follow, and again, the potential for impact is lessened. The greatest impact might be expected on the person who has just sufficient knowledge to understand the content, and enough interest to remain attentive.

Third, the match between the cognitive level of the audience and the cognitive level of the lecture material is important. Learning is less likely to occur when there is serious mismatch, with the lecture content so simple it is boring and irrelevant, or so complex that it is frustrating. Learning is more likely to occur when the topic is particularly relevant to the attendee, who is able to understand sufficiently to recontextualise the issues into his or her own life, and has the opportunity to ask questions for further clarification of the issues. The lecturer's presentation style is also important, in terms of ability to engage the audience, communicate the message and respond to questions.

\section{Constraints on Data Collection}

The nature and format of the lecture series have implications for the amount and type of data that can be collected. We considered a number of points that placed boundaries around our data collection.

\footnotetext{
${ }^{17}$ ibid., p. 18.

${ }^{18}$ M. H. Shamos, The myth of scientific literacy, New Brunswick, NJ, 1995, p. 219.
} 
Because the lectures occupy such a short period, in fairness to the attendees and the lecturer, very little time should be spent gathering data. People come to the lectures for their own purposes, not to have their time taken up by the evaluators. To limit inconvenience to the attendees we decided that data must be collected quickly.

Most people attend lectures irregularly, so it was not possible to rely on a longitudinal process of data collection, privacy was also an issue and we concluded that each person's complete set of data must be collected in one lecture. Because of the time constraints, written rather than oral data were collected.

Apart from its title, there was no information prior to the lecture about its content in terms of knowledge and attitudes that might be affected, so it was not possible to target specific knowledge, understanding or attitudes for measurement. People could be asked for their perceptions of what they learned, but this would cause further problems in how to score the data and how to combine it over lectures with different contents. There may be unexpected outcomes from the lectures, stimulated by discussion of issues peripheral to the topic, for example. Data collection thus needed to be sufficiently broad to capture a range of ideas or outcomes, including cognitive and affective aspects, and be flexible enough for use at any lecture, with a variety of attendees.

The sponsors required some demographic information to determine whom the lectures are reaching and to assist them to target future audiences. This information was also useful to the evaluators, so collecting these data served two purposes. However, sponsors also required other data, such as how people heard about the lectures, whether they wanted further information about the subject or Scitech, and if so, their names and contact addresses. Answering these questions took time away from answering other questions relating to the evaluation.

\section{Development of the Instrument and Data Collection}

A three-part instrument was developed for the evaluation. Part A was used to measure the impact of the lecture and was used as both a pretest and a posttest. Part B (used as a posttest) contained items measuring people's responses to the lecture, in terms of their interest, enjoyment, etc. The items in Part $\mathrm{C}$ collected other information for the sponsors which was peripheral to the evaluation and is not reported further ${ }^{19}$.

The Perceptions about Human Genetics Survey

Most of the development work involved Part A of the questionnaire, the Perceptions about Human Genetics Survey, which was designed to measure attendees' perceptions, ideas and opinions about human genetics. The aim was to measure cognitive and affective ideas relevant to all of the lectures in a way that was sensitive enough to detect any impact the particular lecture might make. Using a generic measure which combined cognitive and affective items, and did not depend on the specific content knowledge, meant data could be combined more easily over several lectures.

The Perceptions about Human Genetics Survey comprises fourteen items. Each item consists of two oppositely worded sentences or phrases separated by seven small boxes. Respondents selected which of the seven boxes between the end statements best represented their view of the idea described ${ }^{20}$. A 'don't know' box was also included. The

\footnotetext{
${ }^{19}$ Details of the full evaluation are available in L. J. Rennie \& G. F. Williams, The Evaluation of a Lecture Series in Human Genetics (Report No. 3), Perth, 1999.

${ }^{20}$ This item format is modified from the traditional semantic differential. Here, bipolar statements rather than bipolar adjectives are used.
} 
wordings of all the items are shown in Figures 1 and 2. There were seven items under each of two headings, Research in Human Genetics and Learning about Human Genetics. Each item was analysed separately, providing a profile of responses to the instrument as a whole. During its development, the questionnaire was revised several times after reviews by a group of science educators and staff from Scitech, and also field-tested with a small external group.

The main purpose of the Perceptions about Human Genetics Survey was to measure the impact of attending a lecture on people's perceptions, ideas and opinions. For this the Survey was used as a pretest-posttest measure. At the beginning of the last six lectures (the period of the evaluation) each person who was attending for the first time was asked to complete the Survey prior to the lecture and again at the end. The pretest was collected before the lecture began and matched to the posttest completed at the end of lecture. Matching was done by using numbered stickers to avoid asking attendees for their names. Although this approach measured impact over only one lecture, this was considered to be the best compromise, as it could not be assumed that any particular person would be present to complete a posttest at some later date. Over the six lectures, a total of 72 first time attendees completed the pretest and posttest.

Audience Response to Individual Lectures

The purpose of Part B of the questionnaire was to measure audience response to individual lectures and it was used as a posttest only for all attendees at each lecture. In addition to the five items shown in Figure 3, participants were asked three open-ended questions. Two of these related to expectations and outcomes. The third question asked for general comments on the series. Data related to age, gender, background knowledge, and suggestions for future series were also collected.

Increasing the Validity of the Research Design

One problem with the pretest-posttest research designs in free-choice settings, like this lecture series, is the lack of a control group against which any change might be compared. In theory a control group with a similar demographic profile would be recruited to attend a placebo lecture and complete the irrelevant Survey on a pretest-posttest basis. But this is unrealistic. As Rennie pointed out in her review of research approaches to learning science in informal contexts, attempts to control the research situation usually end up making it artificial and contrived, seriously undermining validity ${ }^{21}$.

We searched for other ways to increase the validity of our research design. We saw two main problems. The first related to the validity of the Survey. Scrutinised by science educators and field-tested it had face validity and it was easy to complete, but we had not demonstrated that it could detect differences in people's perceptions and opinions about human genetics. The second problem related to the self-selecting audience who attended the lectures. People probably come to the lectures because they have a particular interest in human genetics, and are likely to hold positive views about it. Consequently a ceiling effect might exist on some items.

We decided that insight to both of these problems could be achieved by collecting data from people who were not involved in the lecture series and who might be expected to have different views. Two additional groups of people were targeted: a sample of shoppers at suburban shopping centres to represent the general public, and a sample of day-visitors to Scitech, that is people with some interest in science but not the specific interest in human genetics of those attending the lectures. We used the Perceptions about Human Genetics Survey to build and compare profiles of three groups:

\footnotetext{
${ }^{21}$ L. J. Rennie, 'Learning Science in Informal Contexts: Perspectives from Research', in S. Stocklmayer \& T. Hardy (eds.), Proceedings of the International Conference on Learning Science in Informal Contexts, Canberra, 1999, pp. 1-6.
} 
(i) a sample of 100 non-visitors. These people were sampled at four different shopping centres over five days. People walking past a predetermined point in the mall were approached and invited to respond to the Survey. People were selected using a stratified random sampling method, so as to achieve a similar age and sex profile as the attendees. We found it difficult to attract the interest of shoppers. There were 87 refusals to participate in the research; 21 people before hearing what was required, 62 did not have time, and 4 thought that their English was insufficient for the questionnaire.

(ii) a sample of 100 people who were day visitors to Scitech. Data for this group were collected over three days at Scitech by choosing people using a stratified random sampling procedure so that the final group had a similar age and sex profile as the attendees. There were 19 refusals to complete the questionnaire - 17 people did not have time and 2 who said they 'know nothing about genetics'.

(iii) the 72 people who attended the lectures for the first time. Data from these people were collected by a pretest at the beginning of lectures 4 to 9 and by a posttest at their end.

\section{Results}

The average attendance at each lecture was about thirty-five to forty people. Scitech staff and a few other people did not complete questionnaires, either because they were eager to leave, or because they were accompanying the lecturer. Twice as many females (69\%) as males attended, and 38\% of the attendees were aged between 36 and 55 years. People gave their occupations as health-related professions (32\%), teachers (14\%), university students (15\%), scientists (11\%) and others in clerical or service work. Attendees were also asked to rate their background knowledge in genetics on a 7-point scale from 'extensive' to 'limited'. The average response was very close to the middle of the scale, with an almost even spread across the categories. At each lecture about 30\% of people responded in the two categories nearest 'extensive' and about 30\% responded in the two categories closest to 'limited'. These data suggest that the lecturers faced a challenge to ensure that their presentation catered for a range of background knowledge among the audience.

The results are reported in two sections corresponding to the two parts of the questionnaire. For Part A, responses to the Perceptions about Human Genetics Survey are analysed, including the comparison between the attendees and the non-attendees, and between the pretest and posttest measures of the attendees. Attendees' reactions to the individual lectures are reported from Part B.

\section{Perceptions and Ideas about Human Genetics}

The profiles of the four data sets are presented in Figures 1 and 2, which give the percentage responses to each of the seven items for Research in Human Genetics and the seven items for Learning about Human Genetics, respectively ${ }^{22}$. Each graph shows the percentage of people from each of the four data sets responding to each of the seven response categories and, on the far right, the percentage who responded 'don't know'. Using these data we made two kinds of comparison. The first comparison among the results of

\footnotetext{
${ }^{22}$ These results have the wording of the items arranged so that the right hand side represents the more positive or scientific view about science and human genetics, and the left hand side represents a less positive or scientific view. On the actual questionnaire, some of the questions were worded in the reverse order.
} 
the non-visitors, day visitors, and the pretest data from the attendees was aimed at testing the validity of the Survey and it also helped to describe the attendees by comparing their ideas with those of the non-attendees ${ }^{23}$. The second comparison between the pretest and the posttest responses of the attendees to the Perceptions about Human Genetics Survey, enabled a measure of the impact of that one lecture. Each lecture is different and they possibly have different effects. However, because the numbers were small, the data were collated over all six lectures and the combined results for 72 first time attendees are presented in Figures 1 and 2. These results might be interpreted as representing the average effect of attending one lecture of the series ${ }^{24}$.

\section{People's Perceptions and Ideas about Research in Human Genetics}

It can be seen from Figure 1 that people generally responded positively to the first three items, and that those attending the lectures were the most positive group. In fact, the pretest results of the attendees (third column of data on the graphs) are statistically significantly more positive than those of the non-visitors and day visitors to Scitech (the first two columns on the graphs). The posttest results (the fourth, white column of data) are even more positive than the pretest for the attendees (that is, their responses before the lecture), but there are clear ceiling effects, and the pre/post difference reached statistical significance only for Item 3. As the focus of the lecture was the importance of genetics research to understanding human diseases, this gain is pleasing, especially with such positive opinions to begin with.

\section{Insert Figure 1 about here}

For Item 4, there was a tendency for respondents to believe that knowledge from research in human genetics will be misused. The posttest results showed no clear trend. Overall there were no significant differences between the three groups. The responses for Item 5 are also well spread, but with more people responding at the benefit side of the response categories than the risk side. The posttest responses of the attendees are the most positive, and are statistically significantly more positive than the pretest.

About $50 \%$ of people responded positively to Item 6, 30\% negatively, and $20 \%$ chose ' 4 ', the middle category. The lectures seemed to have little impact on the posttest responses. There wasn't much difference between the attendees and the visitors on Item 7, but the non-visitors (the shoppers) were the least positive, and this difference is statistically significant. Attendance at the lecture had little impact on this idea.

\section{People's Perceptions and Ideas about Learning in Human Genetics}

The results in Figure 2 show that there was strong agreement by all groups to items 8, 9, 11 and 12. For each of these items, the lecture attendees gave the most positive responses, and the differences were significant for Items 9, 11 and 12.

\footnotetext{
${ }^{23}$ To examine the statistical significance of the difference in the responses of the three groups of people we used the Kruskal-Wallis one-way analysis of variance (corrected for ties). In Figures 1 and 2, the items with statistically significant differences in the patterns of responses are marked with *.

${ }^{24}$ We used a Wilcoxon matched-pairs signed-rank test to determine whether the change between pretest and posttest was statistically significant. In Figures 1 and 2, the items with statistically significant differences in the patterns of responses are marked with $\dagger$.
} 


\section{Insert Figure 2 about here}

For Items 8, 9 and 11, the posttest responses of attendees were more positive than those for the pretest, suggesting a favourable impact of the lecture, but because the pretest responses were so positive, there was little room for impact. Only on Item 8 was the difference statistically significant.

Lecture attendees were more positive in their responses to items 10 and 13 than the other two groups of people, and the differences were statistically significant. Comparison between the pretest and the posttest responses for the lecture attendees indicate no change on Item 10, but a statistically significant positive change for Item 13.

The responses to item 14 are well spread out, although it seems that the lecture attendees had a more scientific view of the uncertainty of knowledge than the other groups. The differences for this item are statistically significant, at least between the attendees and the non-visitors. Interestingly, the posttest responses show that a third of the attendees came to the view genetics knowledge as factual, rather than tentative. This item thus had a statistically significant change towards what seems a less scientific view, perhaps an outcome from lecturers who conveyed a persuasive degree of certainty in their presentation.

Two other points can be made from these results. Firstly, the percentage responding 'don't know' decreased on the posttest, suggesting that following the lecture many attendees felt they had sufficient information to form an opinion. Secondly, examination of the results lecture by lecture indicated a good deal of variation in responses to some items. Numbers were too small to do a meaningful analysis of this variation, but it must be remembered that only average results across the lectures have been reported.

\section{How Did the Audience Respond to the Lectures?}

Figure $3^{25}$ summarises the 181 responses relating to how participants perceived each lecture. Overall, attendees thought that the lectures were easy to understand, interesting to the audience, and informative (Figure 3). There were clear differences in response depending on the lecturer involved.

\section{Insert Figure 3 about here}

This variable pattern of results is perhaps not surprising, as different lecturers have different skills of communication. Our own informal observations and notes of the lectures were consistent with these variations. The most successful lecturers engaged the audience by being interested in them, as well as in their own topic, and were available after the lecture for informal questions and discussion over refreshments. Attendees found it helpful if lecturers provided an initial overview of their lecture.

The responses to the open-ended questions gave some insight to the data reported in Figure 3. Most people hoped to gain an increase of knowledge and understanding (84\% of all responses). Within the group some attendees were hoping to gain specific information, whilst others were interested in more general information about genetics, genetic diseases and research. Some attendees mentioned gaining understanding about risks and procedures. A few responses (5\%) referred to updating knowledge in the area of genetics and genetic research. Some responses (4\%) indicated the desire to gain genetics

\footnotetext{
${ }^{25}$ The number of people responding was less than 181, as many completed Part B at more than one lecture.
} 
knowledge for future use, including future career choices. Our conversations with attendees confirmed that some attendees hoped to gain more information about genetic diseases affecting their families.

The second open-ended question asked attendees what, for them, was the most important outcome of the lecture. Many attendees stated that the most important outcome of the lectures was an increase in knowledge and understanding of genetics (72\% of all responses). Increased interest in genetics generally, as well as interest and motivation to learn more about genetics were also common responses (11\%). Other outcomes included gaining an update in the area (3\%), and answering questions that attendees had (3\%). There were comments that focused on social and political factors associated with the lectures and information communicated, such as the importance and possibility of public education and the need for legislation and ethical consideration of research (9\%). A few responses (2\%) indicated some attendees thought the most important outcome of the lectures was the success of the lectures themselves.

A third open-ended question asked for general comments about the lectures and lecture series. The attendees' responses were positive, complimenting the lecture series and applauding the organisers (39\%), and finding the lectures both informative and interesting (22\%). Some responses suggested improvements about the presentation and content, including simplifying the language (22\%).

The need for accessible information was raised (11\%). At each lecture, a take-home folder was available containing useful general information and brochures about activities, the addresses of centres and foundations related to the Hereditary Disease Program. Although the brochures provided contact phone numbers and addresses, it seems that additional information about the specific content of the particular lecture was desired.

At the final lecture, attendees were asked two new questions about the extent to which they thought that their interest in, and knowledge about, human genetics had increased. Their responses are reported in Figure 4.

\section{Insert Figure 4 about here}

The results are particularly positive for interest, with more than $60 \%$ of the audience responding in the top two categories. For increased knowledge, $42 \%$ responded in the top two categories. No person said that their interest or knowledge had not increased. In the minds of the attendees the lecture series has met the aims of the organisers in terms of helping people to understand more about genetics and to increase interest in it.

\section{Discussion}

What has this study achieved in terms of understanding how attendance at lectures can promote people's awareness of and ideas about human genetics? In seeking to answer this question we had to come to grips with the methodological issues inherent in any attempt to assess the outcomes of free-choice activities offering the public a greater understanding of science. Free-choice activities result in outcomes that are very personal, frequently ephemeral, and invariably elusive. This presented us with a range of measurement and research problems that needed to be overcome if these outcomes were to be captured. The solutions and our rationale for them have been outlined above.

Considering the constraints to measuring any change in people's perceptions and ideas brought about by attendance at only one lecture, and the very positive initial responses of the attendees to many items, the results were encouraging. For 10 of the 14 items of the Perceptions about Human Genetics Survey, the number of positive changes 
exceeded the number of negative changes. On average, people became more positive about the practical applications of research in human genetics, that benefits were likely to outweigh risks, that everyone needs some knowledge about human genetics, that it was interesting to them and they were confident talking about it. These results are generally consistent with our hopes that people's experiences in the lectures had helped them to think differently and more confidently about science.

We decided to take a broad perspective, in line with St John and Perry's notion that evaluation should examine how experiences contribute to people's broader relationships with science, rather than restrict our investigation to increases in their specific knowledge. We saw a heterogeneous public exposed to a range of views of science, emphasising the utility of an interactive model of the public understanding of science and the futility of working with a deficit model. The demographic data showed that attendees had a range of occupations, and had quite varied backgrounds in genetics. They gave varying reasons for attending and indicated that they had gained different outcomes. The lectures differed in content and presentation, and attendees responded to lectures differently. For example, attendees appreciated the "human side" of research. Some particularly successful lecturers talked about the research process and dealt with personal and social issues relating to their topic.

Lectures provide an avenue to information and understanding of contemporary scientific issues, and, compared to most media presentations, they can offer effective twoway communication. Lecturers can judge audience reaction and adjust their presentation accordingly, and the audience can ask questions for clarification and extension of information. Was this lecture series successful? According to the attendees' own opinions, their interest and knowledge increased quite substantially. According to the results from the Perceptions of Human Genetics Survey, there were measurable changes even with a ceiling effect on some items. Do these changes indicate success? Not entirely. The demographic data revealed that, like 'Science in the $\mathrm{Pub}^{\prime 26}$, the lectures were not reaching the general community. Most of the people who attended the lectures were students, scientists, nurses and teachers, who are more informed that the average person we surveyed in shopping centres. Thus the problem of how to encourage a wider audience to attend the lectures remains. Nevertheless the organisers have already planned the next lecture series.

\section{Acknowledgments}

We wish to thank Dr Annie Ghisalberti, CEO, Claire Tomlinson, Public Programs Coordinator, and all other staff at Scitech Discovery Centre for their willingness to be involved in this study. We also thank the lecturers who kindly supported our data collection. This project is part of Developing the potential of interactive science and technology centres to promote understanding about science and technology funded by the Australian Research Council. The opinions in this report are those of the researchers and not the funding body.

${ }^{26}$ Stutchbury, op. cit. 


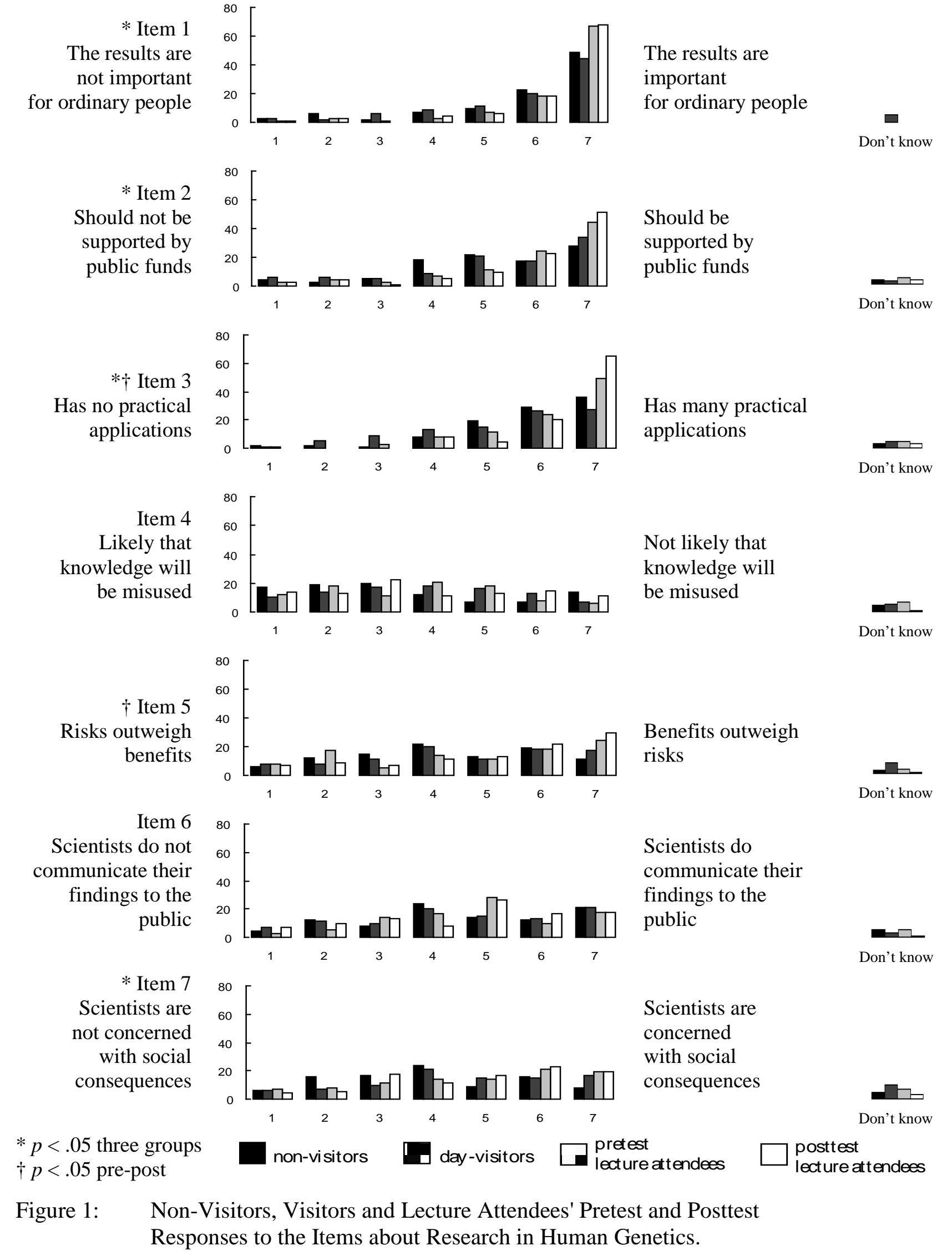




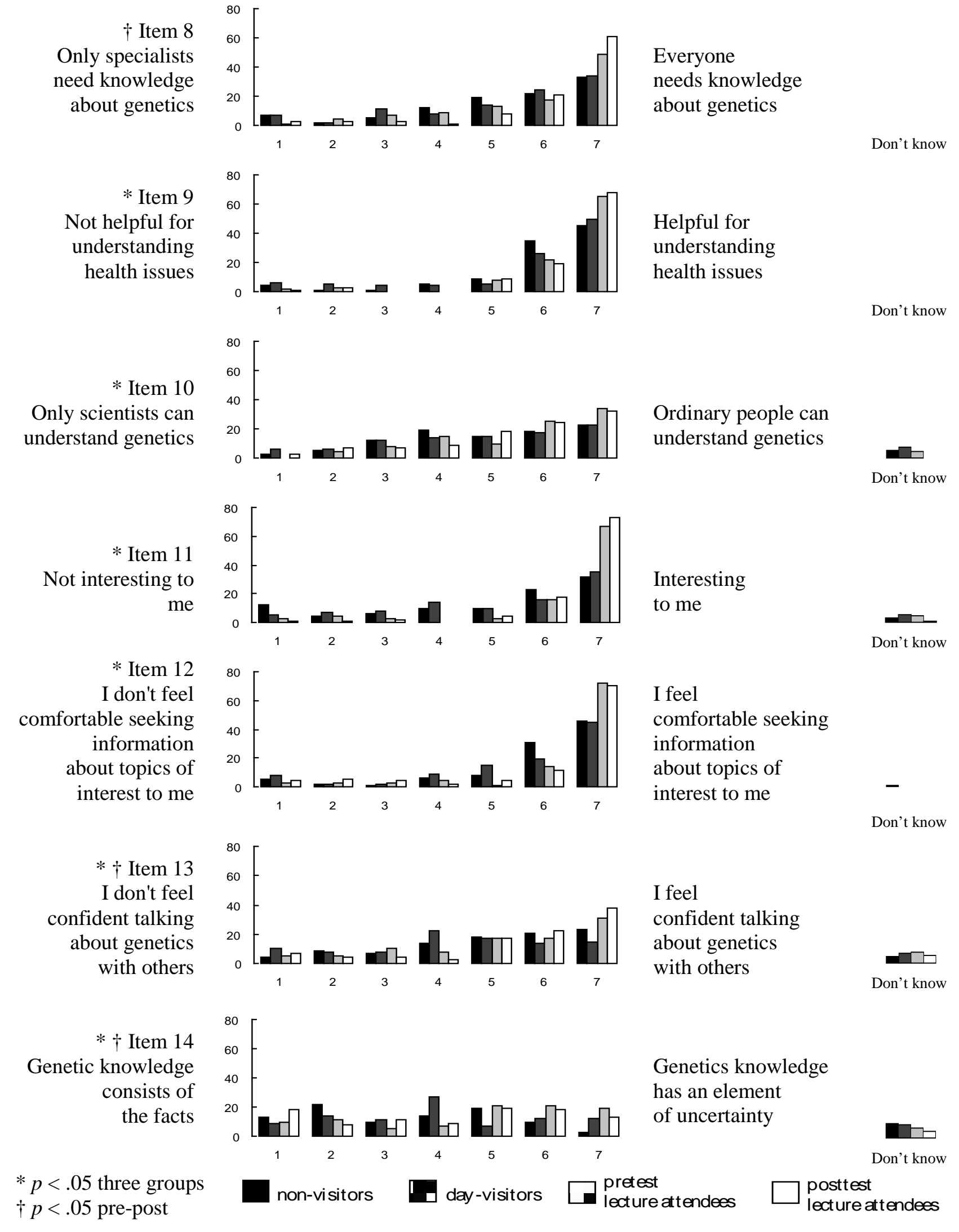

Figure 2: $\quad$ Non-Visitors, Visitors and Lecture Attendees' Pretest and Posttest Responses to the Items on Learning about Human Genetics 

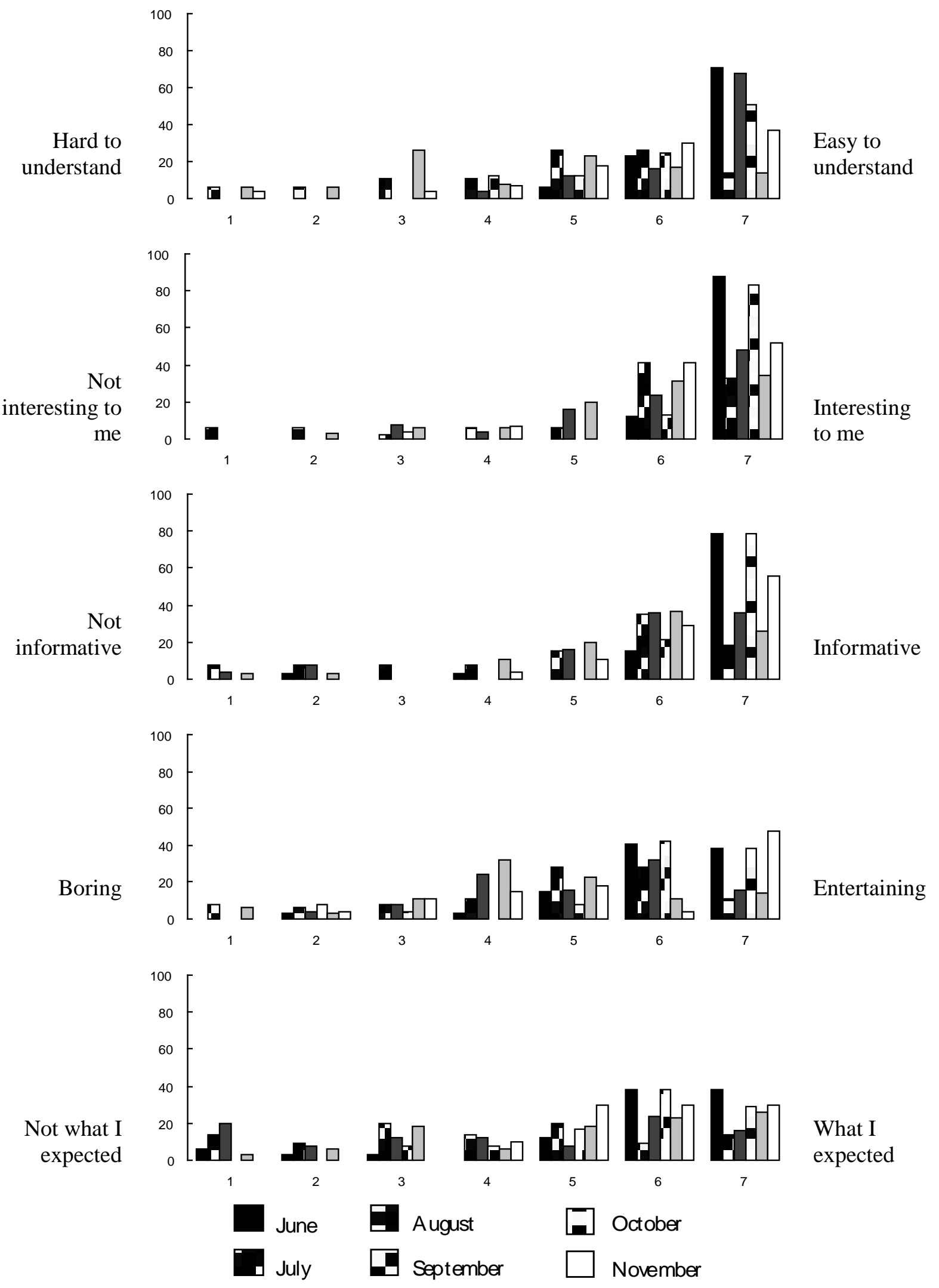

Figure 3. Responses to the Lectures of all Attendees 


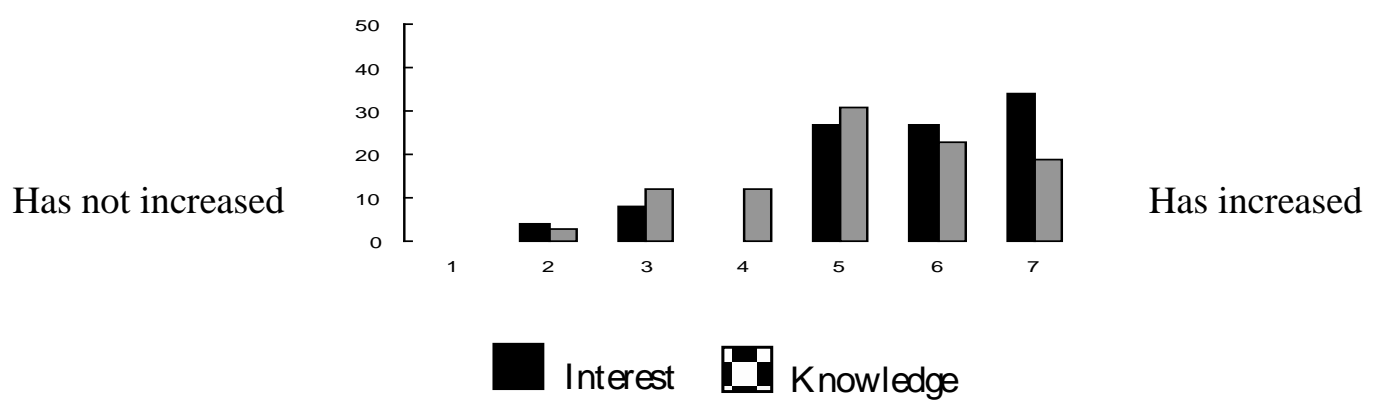

Figure 4 Attendees' perceptions of increase in knowledge and interest through attendance at the lectures. 